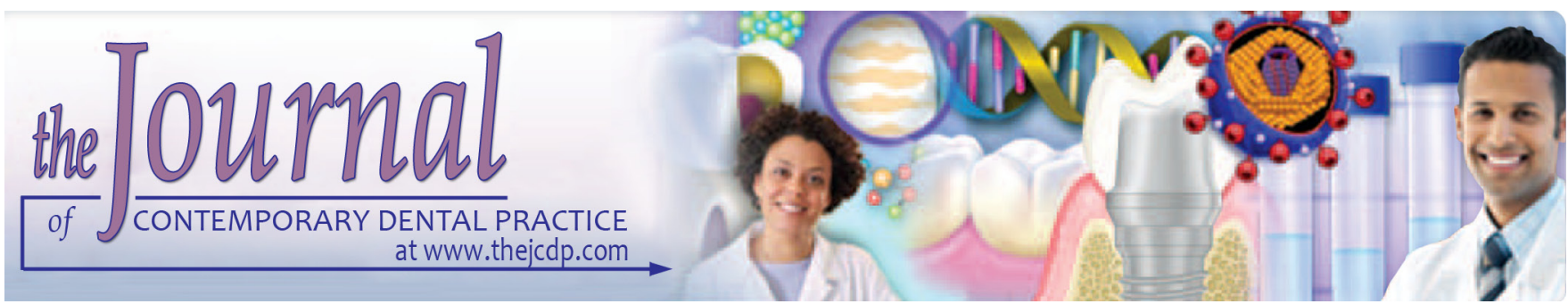

\title{
Root and Root Canal Morphology of Human Third Molar Teeth
}

1Zahed Mohammadi, ${ }^{2}$ Hamid Jafarzadeh, ${ }^{3}$ Sousan Shalavi, ${ }^{4}$ Shilpa Bandi, ${ }^{5}$ Shankargouda Patil

\begin{abstract}
Successful root canal treatment depends on having comprehensive information regarding the $\operatorname{root}(\mathrm{s}) / \mathrm{canal}(\mathrm{s})$ anatomy. Dentists may have some complication in treatment of third molars because the difficulty in their access, their aberrant occlusal anatomy and different patterns of eruption. The aim of this review was to review and address the number of roots and root canals in third molars, prevalence of confluent canals in third molars, C-shaped canals, dilaceration and fusion in third molars, autotransplantation of third molars and endodontic treatment strategies for third molars.
\end{abstract}

Keywords: C-shaped canal, Dilaceration, Endodontic treatment, Root canal, Third molar.

How to cite this article: Mohammadi $\mathrm{Z}$, Jafarzadeh $\mathrm{H}$, Shalavi S, Bandi S, Patil SG. Root and Root Canal Morphology of Human Third Molar Teeth. J Contemp Dent Pract 2015;16(4): 310-313

\section{Source of support: Nil}

Conflict of interest: None

${ }^{1}$ Department of Endodontics, Hamedan University of Medical Sciences, Hamedan; Iranian Center for Endodontic Research Tehran, Iran

${ }^{2}$ Department of Endodontics, Dental Research Center Mashhad University of Medical Sciences, Mashhad, Iran

${ }^{3}$ General Dental Practice, Hamedan, Iran

${ }^{4}$ Department of Conservative Dentistry and Endodontics MS Ramaiah Dental College and Hospital, MS Ramaiah Educational Campus, MSRIT Post, Bengaluru, Karnataka, India

${ }^{5}$ Department of Oral and Maxillofacial Pathology, MS Ramaiah Dental College and Hospital, MS Ramaiah Educational Campus, MSRIT Post, Bengaluru, Karnataka, India

Corresponding Author: Hamid Jafarzadeh, Associate Professor, Department of Endodontics, Dental Research Center, Mashhad University of Medical Sciences, Vakilabad Blvd, Mashhad, Iran, PO Box: 91735-984, Phone: +98-5138829501, e-mail: hamid j365@yahoo.com, JafarzadehBH@ mums.ac.ir

\section{INTRODUCTION}

Successful root canal treatment depends on having comprehensive information regarding the root(s)/canal(s) anatomy. Careful investigation of the main root canal(s) and extracanal(s) should help the clinician to be aware of the negotiable endodontic space, important parts of the root canal system that may cause treatment difficulties. ${ }^{1}$

\section{NUMBER OF ROOTS AND ROOT CANALS}

\section{Maxillary Third Molars}

The number of roots/canals in maxillary third molars varies from one to five. The number of canals in maxillary third molars has been reported from one to six. However, one to three-rooted maxillary third molars are more frequent. ${ }^{2}$ In a study on Thai maxillary third molars, Alavi et $\mathrm{al}^{3}$ showed that $51 \%$ of teeth had three separate roots and $49 \%$ had fused or conical roots. Sidow et $\mathrm{al}^{4}$ showed that $15 \%$ of maxillary third molars had only one root, $32 \%$ had two roots, $45 \%$ had three separated roots, whereas $7 \%$ had four roots. Pécora et $\mathrm{al}^{5}$ showed that $68 \%$ of maxillary third molars had three canals and $34 \%$ had four canals. $\mathrm{Ng}$ et $\mathrm{al}^{6}$ showed that the prevalence of mesiobuccal roots with two canals in maxillary third molars was $39 \%$. A study showed that $34 \%$ of maxillary third molars had four root canals. ${ }^{7}$ In an in vivo study, Stropko ${ }^{8}$ showed that $60 \%$ of maxillary third molars had three canals, $20 \%$ had four canals, and $20 \%$ had two only canals. Cosić et $\mathrm{al}^{9}$ showed that $83.9 \%$ of maxillary third molars had three roots and in $75.1 \%$ had three canals.

\section{Mandibular Third Molars}

The mandibular third molar presents considerable morphological radicular variations: it can have one or several roots whose form varies; it frequently has two roots, a mesial and a distal one, which often merge, and it usually displays two radicular canals. ${ }^{10-12}$ Although 
the third molars anatomy is unpredictable, restorative, prosthetic, and orthodontic considerations often require endodontic treatment of third molars in order for them to be retained as functional components of the dental arch. ${ }^{11,12}$

Gulabivala et $\mathrm{al}^{13}$ showed that $68 \%$ of mandibular third molars had two separate roots, 20\% had fused roots and $11 \%$ had a single C-shaped root. Sidow et $\mathrm{al}^{4}$ concluded that $17 \%$ of mandibular third molars had only one root, $77 \%$ had two roots, $5 \%$ had three roots, and only $1 \%$ had four roots. According to Furri et al, ${ }^{14} 4.6 \%$ of mandibular third molars had one canals, $18 \%$ had two canals, $72.8 \%$ had three canals and $4.6 \%$ had four canals.

A study on an Iranian population showed that $21 \%$ of third molars had one root, $73 \%$ had two roots and $5 \%$ had three roots. ${ }^{15}$ Plotino ${ }^{16}$ presented a mandibular third molar with three separate mesial roots. ${ }^{15}$ Cosić et $\mathrm{al}^{9}$ showed that $56 \%$ of lower third molars had one root and had two root canals in $90 \%$ of cases.

\section{Confluent Root Canals in Third Molars}

According to the Weine classification of the root canal system, there are four types of the root canal. Among these, type two comprises two separate canals leaving the pulp chamber but merging short of the apex to form only one canal. The other name of type two canals of the Weine classification is confluent canals. ${ }^{17}$

Furri et $\mathrm{l}^{14}$ did not report any confluent canals in the mandibular third molars. Pineda and Kuttler ${ }^{12}$ reported $20.6 \%$ of confluent canals in the mesiobuccal roots of the maxillary third molars. Pecora et al ${ }^{10}$ reported $18 \%$ confluent canals in the mesiobuccal roots of the maxillary third molars. Pineda and Kuttler ${ }^{12}$ reported confluent canals in the 18 and $4 \%$ in the mesial and distal roots of the mandibular third molars, respectively. Another study showed that $36 \%$ of the mesial roots of mandibular third molars had confluent canals. ${ }^{14}$

\section{Dilacerated Roots in Third Molars}

Dilaceration is defined as a deviation in the linear relationship of a crown to the related root. The mechanical trauma to the primary tooth is the most important cause of dilaceration in succedaneous tooth. ${ }^{18}$

Hamasha et $\mathrm{al}^{19}$ reported that the incidence of dilacerated roots was $1.33 \%$ for maxillary third molars and $19.21 \%$ for mandibular third molars. Kannan et $\mathrm{al}^{20}$ reported a four-rooted maxillary third molar with dilacerated roots. In an in vivo radiographic study using periapical and panoramic radiographs, Malcic et $\mathrm{al}^{21}$ showed that the incidence of dilaceration was 8.1 and $8.46 \%$ for maxillary third molars using periapical and panoramic radiographs, respectively and 24.1 and $30.92 \%$ for mandibular third molars using periapical and panoramic radiographs, respectively. Using periapical radiographs, Udoye and Jafarzadeh ${ }^{22}$ showed that the incidence of dilacerations in maxillary third molars was $3.7 \%$ and in mandibular third molars was 3.3\%. In another study in a Turkish population, the incidence of dilaceration in maxillary and mandibular third molars was 7.4 and $12.8 \%$, respectively. ${ }^{23}$ A study in an Iranian population showed that the incidence of dilacerated roots in mandibular third molars was $8 \%$ (Table 1$){ }^{15}$

\section{C-shaped Canals}

The pulp chamber of a C-shaped canal has a long ribbonshaped isthmus with at least $180^{\circ}$ arc. Below the orifice, the root anatomy has a wide range of variations. ${ }^{24}$

In an in vitro study using clearing method, Sidow et $\mathrm{al}^{4}$ showed that the incidence of C-shaped canals in maxillary third molars (two-rooted) was 7/150 and in mandibular third molars was 3/150 for both single-rooted and two-rooted teeth. According to Gulabivala et al, ${ }^{13}$ the incidence of C-shape anatomy in mandibular third molars of Thai population was $11 \%$ in vitro. A study in an Iranian population showed that the incidence of C-shaped canals in mandibular third molars was 3.5\% (Table 2). ${ }^{15}$

\section{FUSION}

Fusion is a developmental anomaly refers to the union of two normal distinct tooth germs or a normal germ with a supernumerary one. The etiology of fusion is still unclear, but is likely, in part, related to the physical forces

Table 1: Incidence of dilacerated roots in third molars

\begin{tabular}{lllll}
\hline Authors & Type of study & Year of publication & $\begin{array}{l}\text { Incidence in maxillary } \\
\text { third molars }\end{array}$ & $\begin{array}{l}\text { Incidence in mandibular } \\
\text { third molars }\end{array}$ \\
\hline Hamasha et al & In vivo (PA radiographs) & 2002 & $1.33 \%$ & $19.21 \%$ \\
Malcic et al & In vivo (radiographic) & 2006 & PA radiograph: $8.1 \%$ & PA radiograph: $24.1 \%$ \\
& & & Panoramic: $8.46 \%$ & Panoramic: $30.92 \%$ \\
Udoye and Jafarzadeh & In vivo (PA radiographs) & 2009 & $3.7 \%$ & $3.3 \%$ \\
Miloglu et al & In vivo (PA radiographs) & 2010 & $7.4 \%$ & $12.8 \%$ \\
Kuzekanani et al & In vitro (clearing method) & 2012 & - & $8 \%$ \\
\hline
\end{tabular}


Table 2: Incidence of C-shaped canals in third molars

\begin{tabular}{lllll}
\hline Authors & Type of study & Year of publication & $\begin{array}{l}\text { Incidence in maxillary } \\
\text { third molars }\end{array}$ & $\begin{array}{l}\text { Incidence in mandibular } \\
\text { third molars }\end{array}$ \\
\hline Sidow et al & In vitro (clearing) & 2000 & $7 / 150$ & $3 / 150$ \\
Gulabivala et al & In vitro (clearing) & 2002 & - & $11 \%$ \\
Kuzekanani et al & In vitro (clearing) & 2012 & - & $3.5 \%$ \\
\hline
\end{tabular}

produced by the close contact between two developing teeth. A genetic predisposition has been reported, and racial differences in incidence are evident. . $5,26^{2}$

Hemmig ${ }^{26}$ reported a mandibular third molar fused to a distomolar. Hou and $\mathrm{Tsai}^{27}$ reported a maxillary third molar fused to a distomolar. Shteyer ${ }^{28}$ reported fusion of a mandibular third molar with a distomolar. Morris ${ }^{29}$ reported fusion of mandibular third molar with a supernumerary fourth molar. Fusion of a mandibular third molar with a mandibular second molar has also been reported. ${ }^{30}$ Turell and Zmener ${ }^{31}$ reported both left and right mandibular third molars fused to distomolars. Conte et $\mathrm{al}^{32}$ reported a fusion between a mandibular third molar and a supernumerary tooth (fused to its distal surface).

\section{Treatment Strategies for Third Molars}

As the third molar tooth in the most posterior location the access to it is restricted and so easier handling of treatment procedures would be provided by using special guidelines. Using contra-angle hand-piece with a small head improves the access to third molars.

Furthermore, using short files $(21 \mathrm{~mm})$ and short gates-glidden drills will also enhances accessibility of root canals of third molar teeth. Despite the fact that hand spreaders produce more stress during compaction of gutta-percha, due to the limited access during endodontic treatment of third molars, hand spreaders seem to be more appropriate for lateral compaction technique compared to finger spreaders.

\section{An Important Note during Access Cavity Preparation}

Maxillary third molar usually has a distally tilt whereas the mandibular third molar has a mesially tilt. For preparation of the access cavity in mandibular ones, the handpiece should be placed at the tooth long axis for avoiding mesial perforation.

\section{Autogenous Transplantation}

Autotransplantation is defined as the transplantation of a tooth, either with complete or incomplete root formation, from one site to another in the same individual. ${ }^{33}$ According to Bauss et al ${ }^{34}$ as well as Reich, ${ }^{35}$ if autotrans- plantation is performed accurately, the success rate can reach over $90 \%$.

Third molars can be considered as appropriate candidates to replace hopeless or missed first and second molars, as well as premolars. ${ }^{36}$ To avoid the undesirable consequences following pulp death and root resorption, root canal treatment is usually recommended, in mature teeth, 3 to 4 weeks after autotransplantation. ${ }^{37,38}$ It was recommended that the pulp of teeth with closed apices be extirpated 7 to 14 days after transplantation; otherwise the necrotic pulp and subsequent infection may result in inflammatory resorption and decrease the survival time of the autografts. ${ }^{39}$

The prognosis of autotransplantation is favorable as long as the case is selected precisely, the surgical procedure is performed as atraumatic as possible and the patient is able to follow the postoperative instructions and maintain good oral hygiene measures. ${ }^{39}$

\section{REFERENCES}

1. Mohammadi Z, Shalavi S, Jafarzadeh H. Apical canal confluency: clinical and practical considerations. NY State Dent $\mathrm{J}$ (In Press).

2. Ahmed HM, Abbott PV. Accessory roots in maxillary molar teeth: a review and endodontic considerations. Aust Dent J 2012;57(2):123-131.

3. Alavi AM, Opasanon A, Ng YL, Gulabivala K. Root and canal morphology of Thai maxillary molars. Int Endod J 2002;35(5):478-485.

4. Sidow SJ, West LA, Liewehr FR, Loushine RJ. Root canal morphology of human maxillary and mandibular third molars. J Endod 2000;26(11):675-678.

5. Pécora JD, Woelfel JB, Sousa Neto MD. Morphologic study of the maxillary molars. Part II: External anatomy. Braz Dent J 1991;2(1):45-50.

6. Ng YL, Aung TH, Alavi A, Gulabivala K. Root and canal morphology of Burmese maxillary molars. Int Endod J 2001;34(8):620-630.

7. Pécora JD, Woelfel JB, Sousa Neto MD, Issa EP. Morphologic study of the maxillary molars. Part II: Internal anatomy. Braz Dent J 1992;3(1):53-57.

8. Stropko JJ. Canal morphology of maxillary molars: Clinical observations of canal configurations. J Endod 1999;25(6): 446-450.

9. Cosić J, Galić N, Vodanović M, Njemirovskij V, Segović S, Pavelić B, Anić I. An in vitro morphological investigation of the endodontic spaces of third molars. Coll Antropol 2013;37(2):437-442.

10. Hargreaves KM, Cohen S. Pathways of the Pulp. 9th ed, 2006, p. $148-232$ 
11. Gulabivala K, Aung TH, Alavi A, Ng YL. Root and canal morphology of Burmese mandibular molars. Int Endod J 2001;34(5):359-370.

12. Pineda F, Kuttler Y. Mesiodistal and buccolingual roentgenographic investigation of 7,275 root canals. Oral Surg Oral Med Oral Pathol 1972;33(1):101-110.

13. Gulabivala K, Opasanon A, Ng YL, Alavi A. Root and canal morphology of Thai mandibular molars. Int Endod J 2002;35(1):56-62.

14. Furri M, Tocchio C, Bonaccorso A, Tripi TR, Cantatore G. Apical canal confluency in mandibular molars. Endo 2007; 1(2):53-59.

15. Kuzekanani M, Haghani J, Nosrati H. Root and canal morphology of mandibular third molars in an Iranian population. J Dent Res Dent Clin Dent Prospects 2012;6(3):85-88.

16. Plotino G. A mandibular third molar with three mesial roots: a case report. J Endod 2008;34(2):224-246.

17. Weine FS. Endodontic therapy. 6th ed, 2004. p. 108.

18. Jafarzadeh H, Abbott PV. Dilaceration: review of an endodontic challenge. J Endod 2007;33(9):1025-1030.

19. Hamasha AA, Al-Khateeb T, Darwazeh A. Prevalence of dilaceration in Jordanian adults. Int Endod J 2002;35(11):910-912.

20. Kannan SK, Suganya, Santharam H. Supernumerary roots. Indian J Dent Res 2002;13(2):116-119.

21. Malcic A, Jukic S, Brzovic V, Miletic I, Pelivan I, Anic I. Prevalence of root dilaceration in adult dental patients in Croatia. Oral Surg Oral Med Oral Pathol Oral Radiol Endod 2006;102(1):104-109.

22. Udoye CI, Jafarzadeh H. Dilaceration among Nigerians: prevalence, distribution, and its relationship with trauma. Dent Traumatol 2009;25(4):439-441.

23. Miloglu O, Cakici F, Caglayan F, Yilmaz AB, Demirkaya F. The prevalence of root dilacerations in a Turkish population. Med Oral Patol Oral Cir Bucal 2010;15(3):e441-444.

24. Jafarzadeh $\mathrm{H}, \mathrm{Wu}$ YN. The C-shaped root canal configuration: a review. J Endod 2007;33(5):517-523.

25. Zeylabi A, Shirani F, Heidari F, Farhad AR. Endodontic management of a fused mandibular third molar and distomolar: a case report. Aust Endod J 2010;36(1):29-31.
26. Hemmig SB. Third and fourth molar fusion. Oral Surg Oral Med Oral Pathol 1979;48(6):572.

27. Hou GL, Tsai CC. Fusion of maxillary third and supernumerary fourth molars. Case report. Aust Dent J 1989;34(3):219-222.

28. Shteyer A. Fusion of a third mandibular molar with a distomolar. Oral Surg Oral Med Oral Pathol 1976;42(3):410.

29. Morris DO. Fusion of mandibular third and supernumerary fourth molars. Dent Update 1992;19(4):177-178.

30. Graubard SA. Fusion of a lower second and third molar and macrodontia of a lower first molar. Oral Surg Oral Med Oral Pathol 1977;44(5):817.

31. Turell IL, Zmener O. Endodontic management of a mandibular third molar fused with a fourth molar. Int Endod J 1999;32(3):229-231.

32. Conte M, Lombardi P, Linfant J. A supernumerary tooth fused to the distal surface of a mandibular third molar. J N J Dent Assoc 2002;73(1-2):8-9.

33. Mendes RA, Rocha G. Mandibular third molar autotransplantation-literature review with clinical cases. J Can Dent Assoc 2004;70(11):761-766.

34. Bauss O, Schilke R, Fenske C, Engelke W, Kiliaridis S. Autotransplantation of immature third molars: influence of different splinting methods and fixation periods. Dent Traumatol 2002;18(6):322-328.

35. Reich PP. Autogenous transplantation of maxillary and mandibular molars. J Oral Maxillofac Surg 2008;66(11): 2314-2317.

36. Tsurumachi T, Kakehashi Y. Autotransplantation of a maxillary third molar to replace a maxillary premolar with vertical root fracture. Int Endod J 2007;40(12):970-978.

37. Teixeira CS, Pasternak B Jr., Vansan LP, Sousa-Neto MD. Autogenous transplantation of teeth with complete root formation: Two case reports. Int Endod J 2006;39(12): 977-985.

38. Clokie CM, Yau DM, Chano L. Autogenous tooth transplantation: an alternative to dental implant placement? J Can Dent Assoc 2001;67(2):92-96.

39. Tsukiboshi M. Autotransplantation of teeth. Chicago: Quintessence Publishing Co, Inc; 2001. 